\title{
Assessment of patients' satisfaction and associated factors among outpatients received mental health services at public hospitals of Mekelle Town, northern Ethiopia
}

Haftom Desta', Tesfay Berhe ${ }^{2,3}$ and Solomon Hintsa ${ }^{2,4^{*}}$

\begin{abstract}
Background: Satisfaction is the psychological state that results from confirmation or disconfirmation of expectations with reality. Patients' satisfaction is a healthcare recipient's reaction to salient aspect of the contexts, process and result of their service experience. The aim of this study was to assess patient satisfaction and associated factors among outpatients receiving mental health services at public hospitals in Mekelle town.
\end{abstract}

Objectives: To assess patient satisfaction and associated factors among outpatients receiving mental health services at public hospitals in Mekelle town, northern Ethiopia.

Methods: An institution based cross-sectional study was conducted among 415 outpatients receiving mental health services at public hospitals in Mekelle town from September 2013 to August 2014. The data were collected using standardized, structured pre-tested questionnaire. Participants were selected by systematic random sampling technique. Satisfaction rate was examined with the client satisfaction questionnaire (CSQ-8), having four responses ranging from poor to very good. Descriptive summary using percentages, frequency and graph were used to present study results. Multivariate logistic regressions with 95\% confidence interval (Cl) were used to assess the strength and $p$-value $<0.05$ was used to indicate the significance of the association.

Results: A total of 415 respondents were enrolled, with a response rate of $100 \%$ and magnitude of satisfaction of $72 \%$. The predictors associated with patient satisfaction were higher education ( $\mathrm{OOR}=0.34 ; 95 \% \mathrm{Cl} 0.24,0.97$ ), longer waiting time ( $\mathrm{AOR}=0.01 ; 95 \% \mathrm{Cl} 0.002,0.07)$, having a diagnosis of psychosis $(\mathrm{AOR}=2.36 ; 95 \% \mathrm{Cl} 1.41,5.72)$ were significantly associated with satisfaction.

Conclusion and recommendation: More than one-four of patients receiving mental health services were dissatisfied with the service they received. Improvement in accessibility and availability of drugs, minimizing consultation time $(<45 \mathrm{~min})$ or increasing number of OPD units are important to improve satisfaction.

Keywords: Satisfaction, Factors, Psychiatry, Outpatient, Mental health services

\footnotetext{
*Correspondence: solomonhintsa2013@gmail.com

${ }^{2}$ School of Public Health, College of Health Science, Aksum University,

P. O. Box: 298, Aksum, Ethiopia

Full list of author information is available at the end of the article
} 


\section{Background}

Satisfaction can be defined as the extent of an individual's experience compared with his or her expectations. It is the psychological state that results from confirmation or disconfirmation of expectations with reality [1]. Patients' satisfaction is a healthcare recipient's reaction to salient aspects of the contexts, process, and result of their service experience [2]. Client satisfaction with treatment process may be both influences and be influenced by treatment outcomes. Clients who are not satisfied with a service may have worse outcomes than others. Because, they miss more appointments, leave against advice or fail to follow on treatment plans [2, 3]. Patient satisfaction should be as indispensable to the assessment of quality as to the design and measurement of health care system [4].

Patients' satisfaction, in particular, is subdivided into an orientation towards care and conditions of care. Orientation towards care represents the patient's response from the use of a hospital in view of their hope and expectation which is measured by CSQ-8 (client satisfaction questionnaire). The conditions of care represents specific conditions including the method of treatment, the location of the care institution, the waiting time, the payment, the treatment results that are measured by CIC (community interest company questionnaire) [5].

Unlike clinical process measures, which are strictly facility centered, patient satisfaction is 'patient-centered' process measures. This is an excellent opportunity to involve patients in the process of evaluating the given service and program. Since they are the best source of information, their experiences often reveal how well a hospital system is operating and can stimulate important insight into kind of changes that are needed to close the chasm between the care provided and the care that should be provided. Patients should be allowed to define their own priority and evaluating their care accordingly, rather than having those criteria selected by other professionals [6].

Patient satisfaction is an integral component of health services. Studies of quality of medical care importance are increasing in importance as a component of health research. Consumer opinion of services is being taken into account in the assessment of quality. Thus evaluating a quality of medical care involves the measurement of its benefits to patients and community at large [7]. Patients' ratings of their experiences and satisfaction with health services are a frequently used indicator of service quality [8]. However, there is a limited understanding of how psychiatric units contribute to patients' perceptions of quality [9].

A study conducted in Geneva on patient satisfaction with psychiatric outpatient care reveal that the global satisfaction rate was $93.1 \%$. Whereas the satisfaction level in
Africa ranges 55-83\%. In Ethiopia, the satisfaction level ranges $57.1-99 \%$ [10-18]. The most risk factors associated with patient satisfaction are age, educational status, waiting time, consultation duration, being an in-patient, having a diagnosis of psychosis, contact with services for more than 6 years, marital status, sex of relatives, perceived empathy, perceived technical competency, nonverbal communication and patient [16, 19-27].

There are limited studies about patient satisfaction and associated factors in the study area, so, the aim of this study is to determine the patient satisfaction level and associated factors among outpatients receiving mental health service in public health services of Mekelle town, northern Ethiopia.

\section{Methods}

\section{Study design and area}

Institution based cross-sectional study was conducted from September to August 2014. Tigray regional state has 1 referral hospital, 16 general hospitals, 218 health centers and 668 health posts. Mekelle Town is a capital city of Tigray region, located in $783 \mathrm{~km}$ north of Addis Ababa, Ethiopia. Mekelle Town has two public hospitals; Ayder referral hospital and Mekelle hospital.

\section{Study population}

The sample size was determined using the formula for a single population proportion based on the assumptions 95\% confidence level, 5\% degree of precision and 57\% the proportion of patient satisfaction [19] Taking this assumption 'n' became 374 and $10 \%$ non-response rate; the final sample size was 415 . Systematic random sampling was used to reach the study unit using the sampling frame of patients attending each hospital psychiatric out patient department from patient registration book.

\section{Data collection tools and procedures}

Data were collected using standardized, structured and pre-tested questionnaire through face to face interview from April 13 to May 13, 2014. The questionnaire was first prepared in English then translated to local language (Tigrigna) and back-translated into English to maintain the consistency of the questionnaire by local language translator expertise. The questionnaire address socio-demographic characteristics of the patient and client satisfaction questionnaire (CSQ-8) and community interest company questionnaire (CIC) which assess specific providers and service characteristics, which affects satisfaction.

Global satisfaction rate was examined with the client satisfaction questionnaire (CSQ-8), having four responses ranging from poor [1] to very good [4]. Further, specific reasons for satisfaction or dissatisfaction were studied 
using the modified community interest company (CIC) questionnaire again having four responses ranging from poor [1] to very good [4].

Trained supervisors and data collectors participated in the data collection process from the study area who knows the culture and language of the society. All of the data, collectors were BSc holder in psychiatry and have experience of data collection in mental health survey. Two days of intensive training was given to the data collectors and supervisors on how to conduct the data collection. A brief introduction to data collectors, supervisors and participants had been given before and during the collection process.

\section{Data analysis}

Each completed questionnaire was entered into Epi Info3.5.3 statistical software and then exported into SPSS version 20.0 packages for analysis. Frequencies, proportions and cross-tabulations were used to summarize descriptive statistics of the data. All variables which were $\mathrm{p}<0.25$ at bivariate analysis were entered into multiple Logistic regression. In multiple Logistic regression to develop the final model, OR was estimated at $95 \% \mathrm{CI}$ to show the strength of association and p-value $<0.05$ was used to declare statistical significance.

\section{Ethical considerations}

Ethical clearance was obtained from the Institutional Ethical Review board of school of public health, University of Gondar. Official permission was secured after communication with Mekelle city administrators through a formal letter. Respondents were informed about the purpose of the study, and written consent was obtained from the study participants so as to maintain confidentiality by omitting their names on the questionnaire and on further dissemination of study result. For those participants who were under the age of consent, assent was taken from their attendants and/or themselves when they were independent minor.

\section{Results}

A total of 415 respondents participated in the study, giving a response rate of $100 \%$. Out of the 415 study participants, $262(63.1 \%)$ were males and $128(30.8 \%)$ were in the age range of 30-39. The mean age of the respondents was $35( \pm 12)$ years. Of the total participants, $278(67 \%)$ were Orthodox, 285 (68.7\%) were Tigrian in ethnicity, and 213 (51.3\%) were married. Among all study participants, 129 (31.1\%) were merchants, 308 (74.2\%) were urban residents, 355 (85.5\%) had income in the range of $\geq 750$ (Table 1).

Regarding the diagnosis of the respondents, 170 (40.96\%) had a psychotic disorder, 127 (30.6\%) had
Table 1 Socio-demographic and economic characteristics of patients attending in Mekelle public hospitals, in psychiatry department, Tigray regional state, Ethiopia, August $2014(n=415)$

\begin{tabular}{|c|c|c|c|}
\hline Characteristics & Variables & Frequency & Percent \\
\hline \multirow[t]{2}{*}{ Sex } & Male & 262 & 63.1 \\
\hline & Female & 153 & 36.9 \\
\hline \multirow[t]{5}{*}{ Age (years) } & $<20$ & 10 & 2.4 \\
\hline & $20-29$ & 116 & 28 \\
\hline & $30-39$ & 128 & 30.8 \\
\hline & $40-49$ & 94 & 22.7 \\
\hline & $\geq 50$ & 67 & 16.1 \\
\hline \multirow[t]{2}{*}{ Place of residence } & Urban & 308 & 74.2 \\
\hline & Rural & 107 & 25.8 \\
\hline \multirow[t]{4}{*}{ Educational status } & Informal education & 54 & 13 \\
\hline & Primary education & 73 & 17.6 \\
\hline & Secondary education & 93 & 22.4 \\
\hline & Higher education & 195 & 47 \\
\hline \multirow[t]{4}{*}{ Religion } & Orthodox & 278 & 67 \\
\hline & Muslim & 73 & 17.6 \\
\hline & Protestant & 24 & 5.8 \\
\hline & Others & 40 & 9.6 \\
\hline \multirow[t]{3}{*}{ Marital status } & Single & 93 & 22.4 \\
\hline & Married & 213 & 51.3 \\
\hline & Others & 109 & 26.2 \\
\hline \multirow[t]{3}{*}{ Ethnicity } & Tigre & 285 & 68.7 \\
\hline & Amhara & 31 & 7.5 \\
\hline & Others & 99 & 23.9 \\
\hline \multirow[t]{5}{*}{ Occupation } & Government employee & 55 & 13.3 \\
\hline & Private employee & 95 & 22.9 \\
\hline & House wife & 40 & 9.6 \\
\hline & Merchant & 129 & 31.1 \\
\hline & Others & 96 & 23.1 \\
\hline \multirow[t]{2}{*}{ Income } & $<750$ & 60 & 14.5 \\
\hline & $\geq 750$ & 355 & 85.5 \\
\hline
\end{tabular}

mood disorder, 79 (19.04\%) had nonpsychosis and 39 (9.4\%) had addiction. Only 209 (50.4\%) of the respondents had additional general medical condition and 229 (55.2\%) had a history of admission at these public hospitals.

Regarding the respondents' satisfaction, about onethird, (28\%) of patients scored in the CSQ-8 "low" satisfaction category (below score 21 ), whereas $70.8 \%$ were satisfied (total score $21-27$ ) and $1.2 \%$ very satisfied (total score 27-32). For CSQ-8 items, highest satisfaction rates were quality of service received 315 (75.9\%) followed by satisfaction in an overall, general sense, with the service they received $300(72.3 \%)$ and recommending friends if they are in need of similar services 299 (72\%). While lowest rates were obtained with a 
comeback to the hospital to utilize the service $(70.8 \%)$ and with the amount help they received (70.1\%). This study showed that the global satisfaction that is measured by client satisfaction questionnaire (CSQ-8) was $72 \%$ to the psychiatric service delivered at the outpatient departments of Mekelle public hospitals, which is the sum of satisfied and very satisfied i.e. the total score between 21-26 and 27-32 respectively.

For CIC items, highest rates were found to their relationship with healthcare staff members (75.7\%) and satisfaction with confidentiality and discretion (75.2\%) while the lowest rates were observed with the time they waited before their first appointment (50.2\%). One hundred fifty-five (37.5\%) of the respondents scored in the CIC questionnaire indicated dissatisfied, and the rest 258 (62.5\%) were satisfied and very satisfied (Table 2).

During the multivariate analysis of psychiatric outpatient service satisfaction in relation to all explanatory variables, educational status, waiting time, type diagnosis were found to be significantly associated.

Those higher educational (diploma and above) were 0.34 times less likely satisfied than the rest educational group (AOR $=0.34,95 \% \mathrm{CI} 0.24,0.97$ ). Those complainers of long waiting time were 0.01 times less likely satisfied than those waiting for short time (AOR $=0.01 ; 95 \%$ CI $0.002,0.07$ ) and those from psychosis outpatient were 2.36 times more likely satisfied than respondents from other outpatients (AOR $=2.36 ; 95 \%$ CI 1.41, 5.72) as shown in (Table 3).

\section{Discussion}

Measurement of patients' satisfaction in psychiatric hospitals is important because patients' satisfaction has been correlated with improved hospital administrative measures and quality of care. In addition, measurements of patients' satisfaction allow organizations to identify areas of service delivery that should be improved.

This paper presents a study that is estimated the level of perceived outpatients' satisfaction with mental health services at public hospitals in Mekelle Town. According to this study, the satisfaction level of outpatient mental health service utilization at public hospitals in Mekelle town was $72 \%$. This result is lower than study reported from Geneva on patient satisfaction with psychiatric outpatient care, which is $85.1 \%$. This may be due to the accessibility of the facility and diversity in users' perception [11-13]. On the other hand, a study conducted in Nigeria at Aminu Kano teaching hospital showed that $83 \%$ of the respondents were satisfied [14]. The difference could be due to data collection methods and study design. A study conducted in Mozambique showed that the satisfaction level of patients receiving medical care was $55 \%$, which is lower than the finding of this study [9].

Table 2 Ranked satisfaction rates for the items of Larson's CSQ-8 satisfaction questionnaire and the modified CIC satisfaction questionnaire of respondents in Mekelle public hospitals, psychiatry department, Tigray regional state, Ethiopia, August $2014(n=415)$

\begin{tabular}{lll}
\hline CSQ-8 questionnaire & $\begin{array}{l}\text { Satisfied \% (very good/ } \\
\text { good) }\end{array}$ & $\begin{array}{l}\text { Not satisfied } \\
\text { \% (poor/fair) }\end{array}$ \\
\hline How do you rate the quality of service you received & 75.9 \\
Did you get the kind of service you wanted & 70.6 & 24.1 \\
To what extent of our health services met your needs & 70.8 \\
If a friend were in need of similar help, would you recommend our service to him or her? & 72 & 29.4 \\
How satisfied are you with the amount of help you have received? & 70.1 & 29.2 \\
Have the services you received helped you to deal more effectively with your problems? & 70.8 \\
In an overall, general sense, how satisfied are you with the service you have received? & 72.3 \\
If you were to seek help again, would you come back to our hospital? & 70.8 \\
CIC-questionnaire & & 28 \\
Are you satisfied with confidentiality and discretion? & 74.7 \\
Are you satisfied with your relationship with healthcare staff members? & 75.7 \\
Are you satisfied with staff members' availability? & 69.6 \\
Are you satisfied with the opening hours of this treatment center? & 72.3 \\
Are you satisfied with the length of appointment? & 64 \\
Are you satisfied with frequency of appointment? & 70.6 \\
Are you satisfied with the information received about your treatment (medication)? & 75.2 \\
Are you satisfied with the time you waited before your first appointment? & 50.2 & 29.2 \\
Are you satisfied with the information received about your health status? & 73 & 29.7 \\
\hline
\end{tabular}


Table 3 Association of socio-demographic factors with patient satisfaction among patients getting services in Mekelle public hospitals, Tigray regional state, Ethiopia, August 2014

\begin{tabular}{|c|c|c|c|c|}
\hline \multirow[t]{2}{*}{ Characteristics } & \multicolumn{2}{|c|}{ Level of satisfaction } & \multirow[t]{2}{*}{ COR $(95 \% \mathrm{Cl})$} & \multirow[t]{2}{*}{ AOR $(95 \% \mathrm{Cl})$} \\
\hline & Satisfied (\%) & Not satisfied (\%) & & \\
\hline \multicolumn{5}{|l|}{ Sex } \\
\hline Male & $186(70.9 \%)$ & $76(29.1 \%)$ & 1 & \\
\hline Female & $113(73.8 \%)$ & $40(26.2 \%)$ & $1.154(0.737,1.808)$ & $1.116(0.70,1.77)$ \\
\hline \multicolumn{5}{|l|}{ Age } \\
\hline $18-35$ & 155 (73.8\%) & $55(26.2 \%)$ & $0.892(0.547,1.455)$ & $1.064(0.54,2.06)$ \\
\hline $36-45$ & $51(68 \%)$ & $24(32 \%)$ & $0.754(0.425,1.339)$ & $1.159(0.61,2.58)$ \\
\hline$>45$ & $93(71.5 \%)$ & $37(28.5 \%)$ & 1 & \\
\hline \multicolumn{5}{|l|}{ Marital status } \\
\hline Single & $73(78.4 \%)$ & $20(21.6 \%)$ & 1 & \\
\hline Married & $153(71.8 \%)$ & $60(28.2 \%)$ & $0.699(0.392,1.245)$ & $0.69(0.88,1.23)$ \\
\hline Widowed/divorced & $73(66.9 \%)$ & $36(33.1 \%)$ & $0.565(0.296,1.077)$ & $0.72(0.29,1.07)$ \\
\hline \multicolumn{5}{|l|}{ Diagnosis } \\
\hline Mood & $92(72.4 \%)$ & $35(27.6 \%)$ & $1.168(0.534,2.558)$ & $1.260(0.56,2.83)$ \\
\hline Psychosis & 125 (73.5\%) & $45(26.5 \%)$ & $2.14(1.57,4.74)^{*}$ & $2.36(1.41,5.72)^{*}$ \\
\hline Non psychosis & $55(69.6 \%)$ & $24(30.4 \%)$ & $1.109(0.443,2.341)$ & $1.080(0.45,2.55)$ \\
\hline Addiction & $27(69.2 \%)$ & $12(30.8 \%)$ & 1 & \\
\hline \multicolumn{5}{|l|}{ Educational status } \\
\hline Non formal education & 40 (74\%) & $14(26 \%)$ & 1 & \\
\hline Primary education & $57(79.1 \%)$ & 15 (20.9\%) & $1.247(0.547,2.841)$ & $1.164(0.50,2.66)$ \\
\hline Secondary education & $68(73.1 \%)$ & $25(26.9 \%)$ & $0.952(0.444,2.04)$ & $0.77(0.35,2.1 .70)$ \\
\hline Higher education & 134 (68.7\%) & $61(32.3 \%)$ & $0.41(0.862,0.87)^{*}$ & $0.34(0.24,0.97)^{*}$ \\
\hline \multicolumn{5}{|l|}{ Income } \\
\hline$<750$ & $48(80 \%)$ & $12(20 \%)$ & $1.657(0.846,3.247)$ & $1.37(0.68,2.75)$ \\
\hline$\geq 750$ & 251 (70.7\%) & 104 (29.3\%) & 1 & \\
\hline \multicolumn{5}{|l|}{ Waiting time } \\
\hline$<2 \mathrm{~h}$ & 209 (74\%) & $73(26 \%)$ & 1 & \\
\hline$>2 \mathrm{~h}$ & 90 (67.7\%) & $43(32.3 \%)$ & $0.02(0.003,0.09)^{*}$ & $0.01(0.002,0.07)^{* *}$ \\
\hline
\end{tabular}

* Statistically significant at $(p<0.05),{ }^{* *}$ statically significant at $(p<0.01)$

Differences may be due to the clinical practice difference across the hospitals.

A study conducted at Jimma hospital showed that the satisfaction level of out-patients users was $57.1 \%$, which is lower than the finding of this study. This could be due to the difference in the nature of the service provided and user characteristics at the hospitals, or it might be partly due to data collection method. The other possible reason for the existing difference could due to well-established administration structure and equipped than the stated hospital on mental health services which has a contribution to the positive satisfaction level of the clients. Since the quality of health service is scaling up currently in Ethiopia, time of data collection may be the other reason.

The satisfaction level of outpatient service consumer in Mekelle public hospitals was related to the educational status of the respondents that shows as the educational level of respondents increases the satisfaction level decreases $(\mathrm{AOR}=0.34,95 \% \mathrm{CI}(0.24,0.97)$. This result is in line with findings of a research conducted at Jimma hospital [6]. This shows that patients with relatively higher educational attainment have a greater expectation and they are more critical in analyzing service provided. These could make them less satisfied.

The length of waiting time is found to be significantly associated with the level of respondents' satisfaction on the mental health services provided at these hospitals (AOR $=0.01,95 \%$ CI 0.002, 0.07). It showed that longer waiting time leads to decrease satisfaction level. This may be related to the number of OPDs, number staffs and the type of service either is more detail or not. Most of the time clients are satisfied with the return home without considering the type of the service. Practically health professionals should consider this issue while they give service. 
Another factor that showed significance in this study was the diagnosis of the respondents. Respondents from the psychotic outpatient department were found to be more satisfied compared to respondents from other OPDs (AOR $=2.36 ; 95 \%$ CI 1.41, 5.72). The reason could be due to expectations of the psychotic patients. They could know what the services and they can relate to services given, that makes them more satisfied than the others they do not know the service.

According to this study, the variables: age, sex, marital status, income did not show significant association with the level of satisfaction of the respondents on the service provided at these hospitals. But other studies show that these variables are significantly associated with patients' satisfaction level. The reason could be due to the difference in the diagnosis of patients receiving health services at these hospitals and possible methodological differences in conducting the researches.

Using the standard tool and primary data are some of the strengths of the study. Social desirability bias might have occurred when completing the questionnaire and difficult to establish a temporal relationship between patient satisfaction and associated factors.

\section{Conclusion}

In this study, the satisfaction level of patients receiving mental health services at Mekelle public hospitals was found to be $72 \%$, which is low and needs improvement. Those with higher education, longer waiting time, diagnosed with Psychosis were found to have a statistically significant association with satisfaction. Improvement in accessibility and availability of drugs, minimizing consultation time $(<45 \mathrm{~min})$ or increasing number of OPD units are important to improve satisfaction. Accessibility and availability of drugs, waiting time, number of OPD units and number professionals should be considered to improve satisfaction.

\section{Abbreviations \\ AOR: adjusted odds ratio; BSc: bachelor science; $\mathrm{Cl}$ : confidence interval; $\mathrm{CIC}$ : community interest company; COR: crude odds ratio; CSQ: client satisfaction questionnaire; OPD: out patient department; OR: odds ratio; SD: standard deviation.}

\section{Authors' contributions}

HD originally develops the proposal. HD, SH and TB conduct the study. HD and SH develop the first draft of the manuscript. HD, SH and TB contributed towards data analysis, revision of the draft paper. All authors read and approved the final manuscript.

\section{Author details}

${ }^{1}$ Department of Psychiatry, College of Health Science, Aksum University, P. O. Box: 298, Aksum, Ethiopia. ${ }^{2}$ School of Public Health, College of Health Science, Aksum University, P. O. Box: 298, Aksum, Ethiopia. ${ }^{3}$ Department of Human Nutrition, School of Public Health, Aksum University, Aksum, Ethiopia ${ }^{4}$ Department of Epidemiology and Biostatistics, School of Public Health, Aksum University, Aksum, Ethiopia.

\section{Acknowledgements}

We are glad to public Hospitals in Mekelle for their support in collecting the actual data. We would also like to thank the data collectors and study participants for their participation.

\section{Competing interests}

The authors declare that they have no competing interests.

\section{Availability of data and materials}

The minimal anonymized data is submitted with the manuscript.

\section{Consent to publish}

Not applicable.

\section{Ethics approval and consent to participate}

The study has obtained ethical approval from University of Gondar Institutional Review Board before its commencement. The aim of the study was explained and informed written consent was obtained from each study participants. Permission letter was also obtained from Tigray Regional Health Bureau, and from the hospitals.

\section{Funding}

The study was financially supported by University of Gondar.

\section{Publisher's Note}

Springer Nature remains neutral with regard to jurisdictional claims in published maps and institutional affiliations.

Received: 24 March 2018 Accepted: 5 July 2018

Published online: 11 July 2018

\section{References}

1. Biering $\mathrm{P}$, Jensen $\mathrm{VH}$. Concept of patient satisfaction in adolescence psychiatric care: a qualitative study. J Child Adolesc Psychiatr Nurs. 2010;23(3):143-50.

2. Chaka B. Adult patient satisfaction with nursing care, Master's thesis, June 2005 (unpublished).

3. Andaleb S. Service quality perception and patient satisfaction study of hospitals in developing countries. Soc Sci Med. 2001;52:1359.

4. Jung $\mathrm{M}$, Lee $\mathrm{KH}$, Choi M. Perceived service quality among outpatients visiting hospitals and clinics and their willingness to re-utilize the same medical institutions. Prev Med Public Health. 2009;42(3):151-9.

5. Mintzberg $\mathrm{H}$. The structuring of organization: a synthesis of the research. Englewood Cliffs: Prentice-Hall; 1979.

6. Locker D, Dountt D. Theoretical and methodological issues in sociological studies of consumer satisfaction with medical care. Soc Sci Med. 1978;12:83.

7. Labib PLZ, Brownell L. Factors affecting patient satisfaction with the psychiatric ward round: retrospective cross-sectional study. Psychiatr Bull. 2009;33(3):295-8.

8. Asadi-Lari M, Tamburini M, Gray D. Patients' needs, satisfaction, and health-related quality of life: towards a comprehensive model. Health Qual Life Outcome. 2004;2:22.

9. Brubakk AO. Methods for studying flow dynamics in the left ventricle and the aorta in man. 1979.

10. Helsetilsyn S. Håndbok i drift av psykiatriske.

11. Services Tnmohac. St. prp. Nr. 63 (1997-98): Om opptrappingsplan for psykisk helse 1999-2006; 1998.

12. Bertschy G, Ferrero F. Patient satisfaction with psychiatric outpatient care in Geneva: a survey in different treatment settings, Department of psychiatry, Geneva, University Hospitals, Geneva, Switzerland.

13. Thi PL, Briancon S, Empereur F, Guillemin F. Factors determining inpatient satisfaction with care. Soc Sci Med. 2002;54(4):493-504.

14. Damsa C, Lazignac C, Izycka M, Cicotti A, Hourton G, Andreoli A. A historical overview of the Genevan psychiatry. Ann Med Psychol. 2005; 163:225-60. 
15. Iliyasu Z, Abubakar IS, Abubakar S, Lawan UM, Gajida AU. Patient satisfaction with service obtained from AMINU, KANO teaching hospital, Kano, northen Nigeria. Niger J Clin Pract. 2010;13:371-8.

16. Dagnew M, Zakus D. Community perception on OPD performance of a teaching hospital in Gondar town. Ethiop Med J. 1997;35:153-60.

17. Glisson C. The organizational context of children's mental health services. Clin Child Fam Psychol Rev. 2002;5:233-53.

18. Afework S, Mariam DH, Demeke B. Assessment of quality of services in private clinics in Addis Ababa. Ethiop Med J. 2003:41:267-78.

19. Oljira L, Gebre-Selassie S. Satisfaction with without services at Jimma hospital, South West Ethiopia. Ethiop J Health Dev. 2001;159(3):173-84.

20. Greenwood N, Key A, Burns T, Bristow M, Sedgwick P. Satisfaction with inpatient psychiatric services: relationship to patient and treatment factors. Br J Psychiatry. 1999;174:159-63.

21. Gigantesco A, Picardi A, Chiaia E, Balbi A, Morosini P. Patients and relatives' satisfaction with psychiatric services in a large catchment area in Rome. Eur Psychiatr. 2002;17(3):139-47.
22. WHO Mental health and substance abuse Addis Ababa: WHO; 2001.

23. Zewdie B, Tsion A, Mirkuzie W, Sudhakar M. Determinants of satisfaction with health care provider interactions at health centres in central Ethiopia: a cross sectional study. BMC Health Serv Res. 2010;10:78.

24. Araya M. Post conflict internally displaced persons in Ethiopia, mental disorders and quality of life in relation to traumatic life events, coping strategy, social support, and living conditions, new series.

25. Larson DE, Rootman I. Physician role performance and patient satisfaction. Soc Sci Med. 1976;180:9-10.

26. Mccabe $\mathrm{R}$, Priebe $\mathrm{S}$. The therapeutic relationship in the treatment of severe mental illness: a review of methods and findings. Int J Soc Psychiatry. 2004;50:115-28.

27. Burns T. Community mental health teams: a guide to current practices. New York: Oxford University Press; 2004.
Ready to submit your research? Choose BMC and benefit from:

- fast, convenient online submission

- thorough peer review by experienced researchers in your field

- rapid publication on acceptance

- support for research data, including large and complex data types

- gold Open Access which fosters wider collaboration and increased citations

- maximum visibility for your research: over $100 \mathrm{M}$ website views per year

At BMC, research is always in progress.

Learn more biomedcentral.com/submissions 